\title{
Changes in gallbladder motility and gallstone formation following laparoscopic gastric banding for morbid obesity
}

\author{
Bilal O Al-Jiffry MD ${ }^{1}$, Eldon A Shaffer MD FRCPC ${ }^{3}$, Gino TP Saccone PhD ${ }^{1}$, Peter D owney MBBS ${ }^{2}$, \\ Lilian Kow MBBS PhD FRACS ${ }^{1}$, James Toouli MBBS PhD FRACS ${ }^{1}$
}

BO A I-Jiffrey, EA Shaffer, G T P Saccone, P D owney, L K ow, $J$ Toouli. Changes in gallbladder motility and gallstone formation following laparoscopic gastric banding for morbid obesity. C an J G astroenterol 2003;17(3):169-174.

M orbid obesity is associated with cholesterol gallstone formation, a risk compounded by rapid weight loss. Laparoscopic gastric banding allows for a measured rate of weight loss, but the subsequent risk for developing gallstones is unknown.

MET H OD: Twenty-six normal-weight volunteers (body mass index [BM I \} less than 30) were compared with 14 morbidly obese patients (BM I greater than 40). Gallbladder volumes were measured ultrasonographically, after fasting and following stimulation with intravenous cholecystokinin-octapeptide (CCK-8)

RESU LT S: Preoperatively, fasting gallbladder volume and residual volume after CCK stimulation were both two times greater in the obese group ( $P<0.02$ versus controls). Per cent gallbladder emptying was not different. $G$ allbladder refilling was four times higher in the obese patients $(P<0.01)$. By six weeks postoperatively, the obese patients lost $1.4 \pm 0.1 \%$ body weight per week. Gallbladder emptying decreased $18.4 \%(80.3 \pm 3.9 \%$ to $65.5 \pm 6.9 \%$; $P<0.05)$; residual volume rose one-third (not significant), and refilling fell $60.5 \%$ $(0.43 \pm 0.09$ to $0.26 \pm 0.04 \mathrm{~mL} / \mathrm{min} ; P=0.07)$. Three patients with weight losses of greater than $1.7 \%$ per week developed gallstones; gallbladder emptying fell outside the 95 percentile. By six months, weight loss slowed to $0.5 \pm 0.1 \%$ per week; gallbladder motility improved modestly. No further stones developed.

CONCLU SION: Rapid weight loss following laparoscopic gastric banding impairs gallbladder emptying and when pronounced, gallstones form by six weeks postoperatively. The accompanying reduction in gallbladder emptying, increased gallbladder residual volume and decreased refilling promote gallbladder stasis and hence stone formation.

Key Words: Bariatric surgery; G allbladder motility; G allstone disease; M orbid obesity

\section{Motilité altérée de la vésicule biliaire et forma- tion de calculs après un cerclage laparo- scopique de l'estomac pour obésité morbide}

\begin{abstract}
CONTEXTE : L'obésité morbide est associée à la formation de lithiase biliaire à cholestérol, phénomène accru par la perte de poids rapide. Le cerclage laparoscopique de l'estomac permet de régler la vitesse de la perte pondérale, mais on ne connait pas les risques de formation de calculs qui y sont associés.

MÉT H ODE : N ous avons comparé 26 sujets de poids normal (indice de masse corporelle $[\mathrm{IMC}]<30$ ) à 14 patients atteints d'obésité morbide $(I M C>40)$. Le volume de la vésicule biliaire a été mesuré par échographie, à jeun et après stimulation à l'octapeptide de la cholécystokinine (CCK-8) par voie intraveineuse.

RÉ SU LTAT S : A vant I'opération, le volume de la vésicule biliaire à jeun et le volume résiduel après la stimulation au CCK étaient deux fois plus grands chez les patients obèses que chez les sujets témoins $(P<0,02)$. Le pourcentage de vidange de la vésicule était le même dans les deux groupes. Par contre, le remplissage était quatre fois plus important chez les obèses $(P<0,01)$. Six semaines après l'opération, la perte de poids corporelle s'était faite au rythme de $1,4 \pm 0,1 \%$ par semaine. La vidange de la vésicule avait diminué de $18,4 \%$ (de $80,3 \pm 3,9 \%$ à $65,5 \pm 6,9 \% ; P<0,05$ ); le volume résiduel avait augmenté du tiers (non significatif) et le remplissage avait diminué de $60,5 \%$ (de 0,43 $\pm 0,09$ à $0,26 \pm 0,04 \mathrm{ml} / \mathrm{min}$; $P=0,07$ ). Des calculs se sont formés chez trois patients dont la perte de poids avait été supérieure à 1,7\% par semaine; la vidange de la vésicule était sortie du $95^{\mathrm{e}}$ rang centile. A u bout de six mois, la perte de poids avait ralenti $(0,5 \pm 0,1 \%$ par semaine); la motilité de la vésicule s'était quelque peu améliorée. II n'y a pas eu d'autres formations de calculs.

CONCLUSION : La perte de poids rapide après le cerclage laparoscopique de l'estomac altère la vidange de la vésicule biliaire et, lorsque le phénomène est marqué, cela donne lieu à la formation de calculs dans les six semaines suivant l'opération. La diminution de la vidange de la vésicule, l'augmentation du volume résiduel et la diminution du remplissage favorisent la stase biliaire, d'où formation de calculs.
\end{abstract}

G allstones are common. The prevalence in developed J countries ranges between $6 \%$ and $16 \%$ in adults, and is especially high in women during their reproductive years. This frequency increases to $30 \%$ in morbidly obese women (1). A Ithough treatment for mild obesity is mainly dietary, major surgery plays a role in those who are morbidly obese. Both dieting and surgery, however, are associated with a heightened risk of developing gallstones. Those losing considerable weight are at an even greater risk of stone formation, when compared with similarly obese persons on a weight maintenance diet (2). Rapid weight loss generates an 18 -fold increase in gallstone development (3), whereas less rapid weight loss appears relatively safe. W eight loss of up to $1.5 \mathrm{~kg}$ per week, or up to $1 \%$ to $1.5 \%$ of the total body weight per week is not associated with

${ }^{1}$ D epartment of $\mathrm{G}$ eneral and D igestive Surgery; ${ }^{2} \mathrm{D}$ epartment of M edical Imaging, Flinders U niversity of South A ustralia, A delaide, A ustralia ${ }^{3}$ D ivision of $\mathrm{G}$ astroenterology, D epartment of M edicine, U niversity of $\mathrm{C}$ algary, $\mathrm{C}$ algary, A lberta

C orrespondence and reprints: Dr Eldon A Shaffer, D ivision of $\mathrm{G}$ astroenterology, $\mathrm{H}$ ealth Science $\mathrm{C}$ entre, Faculty of M edicine, U niversity of C algary, 3330 H ospital D rive N orthwest, C algary, A lberta T 2N 4N 1. Telephone 403-210-9325, fax 403-210-9340,

e-mail shaffer@ucalgary.ca

Received for publication A ugust 14, 2002. A ccepted D ecember 13, 2002 
any increase in stone formation (4).

The livers of obese patients secrete abnormal bile, containing an excess of cholesterol relative to its solubilizing capacity. In the presence of a nucleating factor, the excess cholesterol then precipitates from this supersaturated bile. $G$ allbladder stasis al so contributes to chol esterol gallstone formation, allowing the time necessary for the microcrystals of cholesterol to precipitate, be retained, aggregate and subsequently grow into macroscopic stones. A fter an overnight fast, obese people have larger gallbladder volumes compared with those of normal sized individuals $(5,6)$. Body mass index $(\mathrm{BM})$, however, is not the sole determinant of gallstone formation. Large people in general, regardless of their BMI, also have large fasting gall Ibladder volumes, but do not necessarily devel op gallstones (7), perhaps because of a more normal cholesterol solubility of bile.

Reports to date have been divergent in terms of the gallbladder motility exhibited by obese individuals compared with that of 'normal' lean subjects. Some have shown impaired gallbladder motility in obese persons (5,8-11), whereas others have reported no difference $(12,13)$. Certainly, impaired gallbladder emptying has been implicated when obese patients consume a very low calorie diet $(5,12,14)$ or after surgery has induced weight reduction (3). Studies in human and animal models suggest that gallbladder emptying is impaired even before the gallstones become evident (15-18). The use of agents to pharmacologically stimulate the gall bladder to empty more frequently can prevent this eventuality (19).

The effect of weight loss after the laparoscopic insertion of an adjustable gastric band on gallbladder motility has not been determined. This form of surgery has multiple advantages: performed laparoscopically, it results in an early discharge from hospital (one to three days); allows the initiation of oral fluids soon after recovery from anaesthesia; and it maintains the normal integrity of the gastrointestinal tract. The weight loss is gradual over time (20). Therefore, it should represent a lesser risk for gallstone formation.

The aims of the present study were to: determine if gallbladder size and emptying were abnormal in obese people; determine the frequency of gallstone formation after gastric reduction surgery for obesity; and define the effects of weight reduction following gastric banding on gal lbladder motor function.

\section{Study group}

\section{METHODS}

C ontrols: Twenty-six (14 men, 12 women) healthy volunteers with a BMI of less than $30 \mathrm{~kg} / \mathrm{m}^{2}$ were recruited based on the absence of any previous clinical history of biliary symptoms or surgery, and their not receiving any medication (eg, calcium channel blockers, antispasmodic medications, progesterone) or having a clinical condition (eg, diabetes mellitus) that could affect gallbladder motility. This control group provided measurements for average sized, healthy adults with a normal weight.

0 bese patients: Fourteen (one man, 13 women) morbidly obese patients with a BM I of greater than 40 , or a BM I greater than 35 plus the presence of a comorbid factor(s) (ie, diabetes, cardiac conditions, hypertension and/or orthopedic problems), were assessed and found to be fit for elective laparoscopic surgery, using gastric banding to reduce food ingestion. Type II diabetes was present in three patients. $\mathrm{N}$ one consumed any medication known to affect gallbladder motility, including female sex hormones.
A Swedish adjustable gastric band (O btech M edical A G, StA ntons- $G$ asse, Switzerland) was inserted laparoscopically, to create a proximal gastric pouch with a volume of approximately 20 to $30 \mathrm{~mL}$. $U$ sing the pars flaccida technique for placement of the gastric band, a proximal gastric pouch was fashioned with a volume of approximately 20 to $30 \mathrm{~mL}$. The insertion of the laparoscope allowed visualization of the liver and upper abdomen. Retraction of the liver upwards exposed the gastroesophageal junction and the spleen. A grasper introduced via the working ports retracted the stomach down wards to expose the angle of $\mathrm{H}$ is at the gastroesophageal junction. Minimal dissection was done at the angle of $\mathrm{H}$ is to open the peritoneum and identify the left crus and then the right crus through the lesser omentum. All dissection was done without division of tissue and hence there was little chance of endangering the vagi. A reticulated grasper was inserted between the crura and the esophagus and the adjustable gastric band was attached to it so as to place it in the pars flacida position. The band was secured by multiple sutures.

A Il patients had an initial gallbladder ultrasound within one month of their surgical procedure. Subsequent studies were preformed at six weeks and at six months following surgery, respectively. No major complications followed the surgery. A II patients commenced oral intake on the first postoperative day and were discharged within three to seven days.

\section{Study protocol}

Gallbladder volumes were measured after an overnight fast. Cholecystokinin-octapeptide (CCK-8) (KinevacT M, Bracco Diagn ostics/Diagnostiques $\mathrm{C}$ anada Inc, $\mathrm{M}$ ississauga, $\mathrm{O}$ ntario) was then infused intravenously at $20 \mathrm{ng} / \mathrm{kg} / \mathrm{h}$ over $45 \mathrm{~min}$ to induce gallbladder emptying. Gallbladder volumes were measured at three intervals: before initiating the infusion (ie, after an overnight fast) and then at 15 min intervals; during the C C K-8 infusion (conditions that stimulate gallbladder emptying); and for a further $45 \mathrm{~min}$ after stopping the CCK (conditions when gallbladder refilling commences). The duration of the last two measures, therefore, was $90 \mathrm{~min}$.

\section{U Itrasound measurement of gallbladder volume}

This was carried out using a real time ultrasound device (Diasonic DRF1, Diasonics Inc, USA) with either a linear $3.5 \mathrm{MHz}$ or a $5 \mathrm{M} \mathrm{H}$ z transducer, for both controls and obese patients, depending on the patient's build. Longitudinal and transverse scans of the gallbladder were obtained following deep inspiration, using abdominal markers to standardize the gallbladder views. A ny measure for these two dimensions used the largest diameter of the gall lbladder. The gallbladder volume was calculated using the ellipsoid method (21).

Per cent gallbladder emptying was calculated as:

(Fasting volume - residual volume at $45 \mathrm{~min}$ ) / (fasting volume) $\times 100$.

The residual gall bladder volume was taken at the nadir of emptying. This smallest volume occurred by $45 \mathrm{~min}$ into the C CK-8 infusion.

The gallbladder refilling rate was calculated as:

( $G$ allbladder volume at $90 \mathrm{~min}$ - gallbladder volume at 75 $\min / 15 \mathrm{~min}$ ).

The rationale for choosing to calculate the refilling time after 75 min was to allow more than five biological half-lives of C CK-8 (22), so that virtually no residual C CK -8 should remain in the cir- 
TABLE 1

Demographics and gallbladder measurements of both male and female volunteers

\begin{tabular}{lll}
\hline & Men $(\mathbf{n = 1 4})$ & Women $(\mathbf{n = 1 2})$ \\
\hline Age & $35(23-57)$ & $41(25-59)$ \\
Body mass index & $26.4 \pm 0.7$ & $23.7 \pm 0.6$ \\
Gallbladder volume $(\mathrm{mL})$ & $22.3 \pm 2.1$ & $20.1 \pm 2.4$ \\
Gallbladder emptying $(\%)$ & $76.2 \pm 4.3$ & $77.8 \pm 2.4$ \\
Gallbladder residual & $4.9 \pm 0.9$ & $4.2 \pm 0.5$ \\
$\quad$ volume $(\%)$ & & \\
Gallbladder refilling $(\mathrm{mL} / \mathrm{min})$ & $0.10 \pm 0.04$ & $0.10 \pm 0.05$ \\
\hline
\end{tabular}

Data are presented as mean \pm SEM, except for age (years) which is presented as median (range). No statistical differences were noted between the two groups

culation. Two of the present authors ( $B O A-J$ and PD) independently assessed the ultrasound results; any differences were resolved by consensus. R epeat ultrasound studies to verify the findings were performed on those who developed gallstones. The range of accuracy of the ellipsoid method of ultrasound volume measurement is quite accurate (23); intraobserver and interobserver variation is usually within $10 \%$. With large gallbladders, the variation is almost al ways less than $10 \%$. W hen the gallbladder is small, the frequently variation is greater than $10 \%$, but the absolute difference is small. The accuracy would, therefore, appear sufficiently precise to sustain the close significance in the relatively small number of patients who developed cholelithiasis.

This study received approval from the $C$ linical R esearch Ethics Committee of Flinders Medical Centre, Flinders U niversity of South A ustralia.

\section{Statistical analysis}

The statistics program SPSS (10 Edition SPSS Inc, USA) was used to perform an analysis of variance (ANOVA). The Bonferroni correction or the nonparametric Mann-Whitney analysis were used where appropriate. A $\mathrm{P}<0.05$ was accepted as significant.

\section{$\mathrm{N}$ ormal versus obese}

\section{RESU LT S}

Table 1 summarizes the age and BM I of both male and female volunteers. There was no difference between the two sexes in any of the parameters measured in the study. C ombining both men and women was therefore appropriate, although an obvious difference in the distribution of the sexes existed between the healthy and the obese groups ( $P=0.005$ by Fisher's exact test).

Table 2 provides the age, sex and BM I of both the volunteers and the obese patients. There was no difference in age between the controls (volunteers) and the obese group. No effort was made to match the sex distribution in the obese group because women predominantly sought this type of surgery. Gallbladder volumes after an overnight fast were markedly increased in the obese patients before surgery. Their gallbladders were twice as large as those of the volunteers. Following the CCK-8 infusion, their gallbladder residual volumes were double those of the normal weight controls. The per cent gallbladder emptying with C CK-8, however, did not differ between the two groups. Because of their larger fasting gallbladder volume, the absolute volume of bile emptied was greater in the obese patients $(34.7 \pm 5.4 \mathrm{~mL}$, compared with that of the volunteers $[16.7 \pm 1.5 \mathrm{~mL}, P<0.05])$. Besides the

\begin{tabular}{|c|c|c|c|}
\hline & $\begin{array}{l}\text { Volunteers } \\
(n=26)\end{array}$ & $\begin{array}{c}\text { Obese patients } \\
(n=14)\end{array}$ & $P$ value \\
\hline$\overline{\text { Age }}$ & $35(23-59)$ & $34(25-57)$ & \\
\hline Sex (male:female) & 14:12 & 1:13 & \\
\hline Body mass index & $25.1(21.8-29.5)$ & $45.3(36-61.5)$ & $<0.01$ \\
\hline Gallbladder volume (mL) & $21.3 \pm 1.5$ & $43.0 \pm 6.6$ & $<0.02$ \\
\hline Gallbladder emptying (\%) & $76.91 \pm 2.5$ & $80.3 \pm 3.9$ & NS \\
\hline $\begin{array}{l}\text { Gallbladder residual } \\
\text { volume (\%) }\end{array}$ & $4.6 \pm 0.5$ & $8.3 \pm 2.7$ & $<0.02$ \\
\hline $\begin{array}{l}\text { Gallbladder refilling } \\
(\mathrm{mL} / \mathrm{min})\end{array}$ & $0.10 \pm 0.02$ & $0.43 \pm 0.09$ & $<0.01$ \\
\hline
\end{tabular}

Data are presented as mean \pm SEM, except for age (years) and body mass index which are presented as median (range). NS Not significant

larger gallbladder volume with fasting and the increased residual volume after the CCK-8 infusion, the gallbladder refilling rate was four times greater in the obese compared with that of the volunteers $(P<0.01)$.

\section{0 bese patients six weeks after surgery}

O f the 14 patients enrolled at the beginning of this study, three developed gallstones, while three others elected not to continue in the study. The BMI decreased in the remaining 11 patients from $44.5 \pm 3.2$ to $40.4 \pm 2.8$ (or $1.4 \pm 0.1 \%$ body weight per week), from that recorded preoperatively compared with six weeks following surgery, respectively. In these obese patients, the fasting gallbladder volume decreased $25 \%$, from $43.0 \pm 6.6 \mathrm{~mL}$ before surgery to $29.1 \pm 6.1 \mathrm{~mL}$ at the sixth postoperative week, respectively (Figure $1 \mathrm{~A}$ ). They also experienced a significant reduction in gallbladder emptying, from $80.3 \pm 3.9 \%$ to $65.5 \pm 6.9 \%(P<0.05)$ (Figure $1 B)$. Their emptying remained less than that of the volunteer control $(P<0.05)$. This decrease in gall bladder emptying allowed the gallbladder residual volume to increase by one-third, from $8.3 \pm 4.5 \mathrm{~mL}$ to $11.2 \pm 4.5 \mathrm{~mL}$, between the preoperative and six weeks postoperative measurements, respectively. A Ithough this increase in residual volume did not reach significance (Figure $1 C$ ), all values remained higher than those in the control group $(P<0.05)$. $\mathrm{G}$ allbladder refilling decreased $39.5 \%$, from $0.43 \pm 0.09 \mathrm{~mL} / \mathrm{min}$ to $0.26 \pm 0.04 \mathrm{~mL} / \mathrm{min}$ between the preoperative and six weeks postoperative measurements respectively, at a significance of $\mathrm{P}=0.07$ (Figure 1D). Refilling remained well above the volunteer group $(\mathrm{P}<0.05)$.

The three patients who developed stones all had a weight loss of greater than $1.7 \%(1.73,2.01$ and $2.33 \%$, respectively, for each) of their total body weight per week over the six weeks. N one were diabetic. Indeed, two out of the three patients were above the 95 percentile (mean $\pm 2 S D$ ) of weight loss for this group (Figure 2). These three al so exhibited a lower gallbladder emptying, well outside the 95 percentile when compared with the rest of the group (Figure 2). Two of these three patients also were consistently out of the 95 percentile range for the obese group, in terms of gallbladder volume, residual volume and refilling rate (data not shown).

\section{0 bese patients six months following surgery}

O ne of the 11 patients elected not to continue with the study. O ne of the three patients who developed stones experienced an attack of acute cholecystitis that required surgery. $\mathrm{N}$ ine 


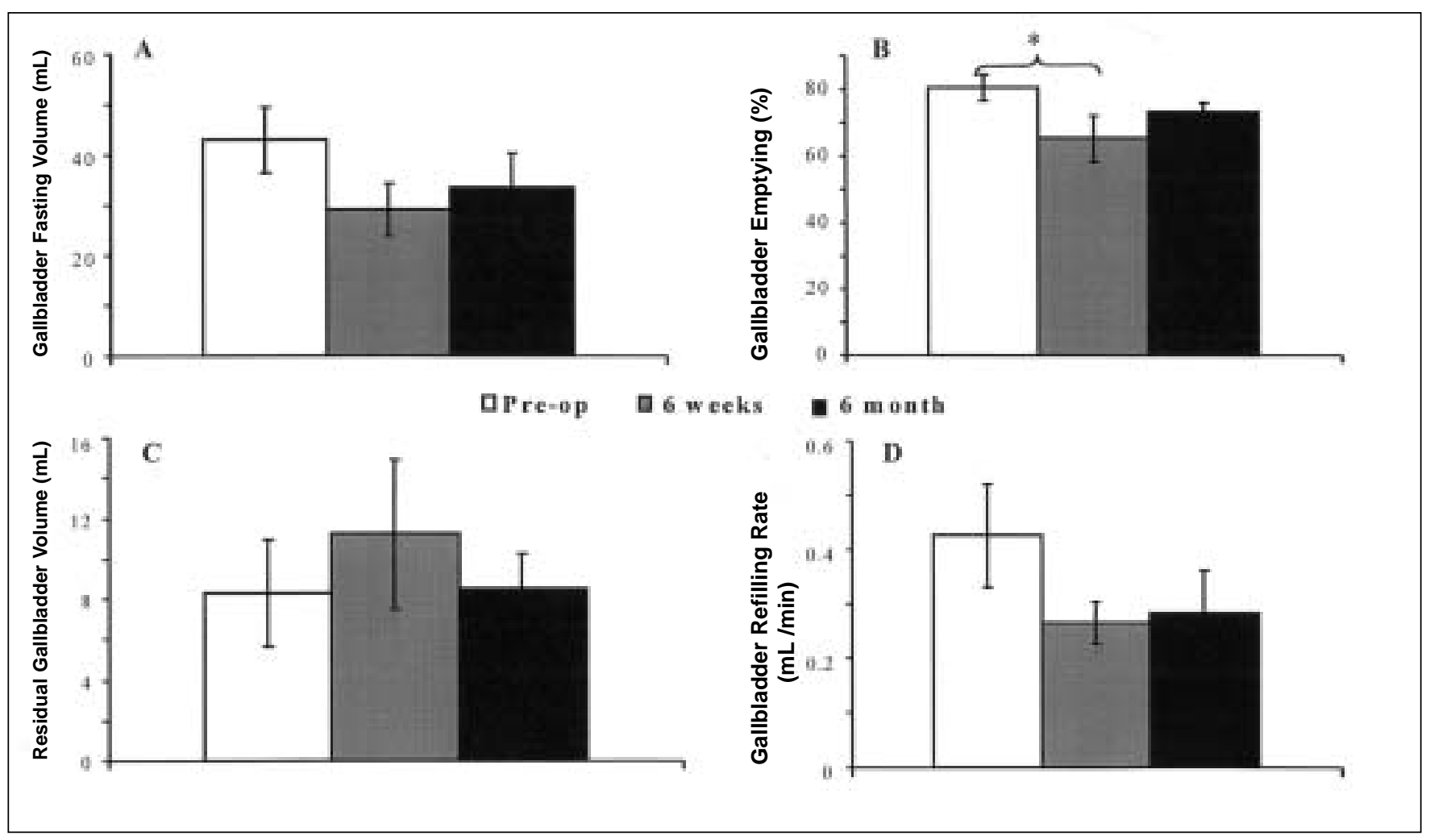

Figure 1) * means $P<0.05 . G$ allbladder measurements for the obese patients at three time periods: preoperatively, six weeks postoperatively and six months postoperatively ( $\mathrm{n}=14,11$, and 9 respectively). A) $\mathrm{G}$ allbladder fasting volume; B) $\mathrm{G}$ allbladder emptying with cholecystokinin; C) $G$ allbladder residual volume; and D) G allbladder refilling rate. G roup data are presented as mean \pm SE M .

patients completed the six month study. From six weeks to six months, their BMIs further decreased from $41.9 \pm 3.5$ to $37.4 \pm 2.6$ (or $0.5 \pm 0.1 \%$ body weight per week). Gallbladder measurements changed modestly towards those found before surgery. The gallbladder volume increased from $29.1 \pm 6.1 \mathrm{~mL}$ at six weeks to $33.5 \pm 6.7 \mathrm{~mL}$ at six months while emptying increased from $65.9 \pm 6.9 \%$ to $74.3 \pm 2.9 \%$ (not significant). The residual volume decreased from $11.2 \pm 4.5 \mathrm{~mL}$ at six weeks to $8.5 \pm 1.8 \mathrm{~mL}$. Gallbladder refilling rate remained virtually unchanged between six weeks and six months (Figures 1A, 1B, $1 C$ and $1 D)$, but remained significantly above that of the volunteers $(P<0.05)$.

Of the three patients who developed gallstones at six weeks, one required a cholecystectomy. A nother still had stones at six months but had no symptoms. In the third patient, the gallstones disappeared and were not evident even on repeat ultrasonography. This latter patient exhibited an improved gallbladder emptying from $56.4 \%$ to $67.1 \%$, while weight loss of $2.3 \%$ per week at six weeks fell to $0.3 \%$ per week by six months. This patient was also the only one of the three whose gallbladder volume, residual volume and refilling rate fell within the 95 percentile of the group at six weeks when gallstones were first detected.

\section{DISC U SSION}

0 bese patients, as shown here, exhibited a significant increase in their gallbladder volume with the same per cent emptying response to CCK-8 as the controls, but yielded a significant increase in the gallbladder residual volume and refilling rate. The present study further demonstrates that very obese women who rapidly lose weight after laparoscopic gastric banding are at high risk for developing gallstones. Following such surgery, $27 \%$ (three of the 11 patients) acquired gallstones at six weeks. Their rate of weight loss was $1.7 \%$ of the total body weight per week for the six weeks following surgery. No further stones developed thereafter. Instead, one of the stones disappeared. A II three patients exhibited a greater per cent weight loss per week and much reduced gallbladder emptying (outside the 95 percentile), compared with that of the obese patients without gallstone formation. Two out of the three patients differed from the others in terms of larger gallbladder fasting and residual volumes, and lower gallbladder refilling rates. The third patient was not different, and by six months, the gallstones had disappeared on ultrasound. A t six months, all patients showed a trend towards their preoperative measurements.

The current study did not demonstrate any differences between the male and female volunteers in their gallbladder motility in terms of emptying, refilling or gallbladder volume. A sex difference in the incidence of gallstones exists between men and women (24-26), but this is not linked to any proposed difference in gallbladder motility caused by the female sex hormones $(27,28)$. M en generally have greater fasting gallbladder volumes than women (29). It thus seemed reasonable to combine the sexes, because women predominated in these morbidly obese patients seeking bariatric surgery.

$\mathrm{G}$ all bladder volume after an overnight fast and following a standard infusion of C CK-8 was different in the obese compared with that of the normal controls, as has been demonstrated previously $(5,7)$. Increased gallbladder volume with poor mixing and a long residence time favours the develop- 


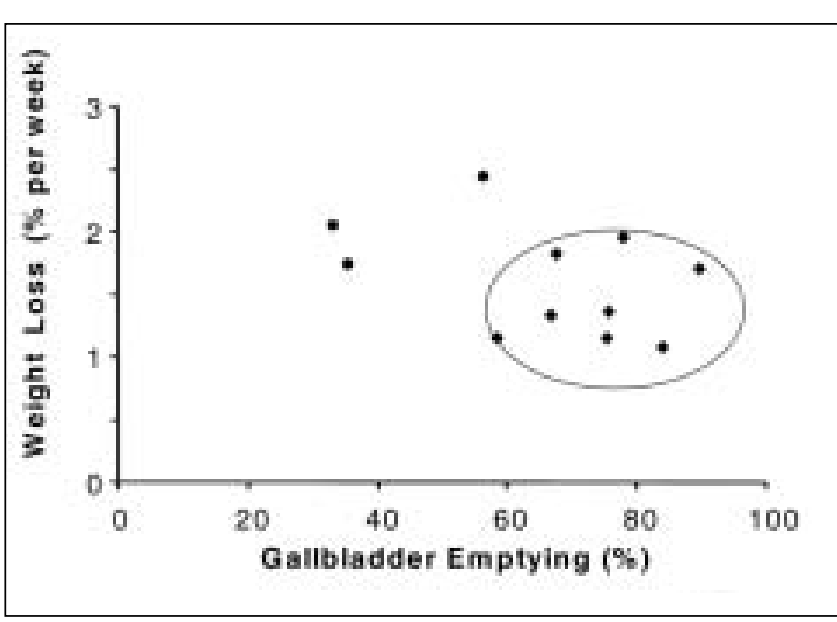

Figure 2) $\mathrm{G}$ allbladder emptying in relation to the percentage of weight loss per week at six weeks following surgery. The circle represents the mean $\pm 2 S D$ for 95 percentile of the group that did not develop gallstones. Symbols: T he diamond shaped markers inside the circle represent the eight patients who did not develop gallstones. The remaining round markers represent the three patients who developed gallstones at six weeks

ment of biliary sludge and hence stone formation (30). Further, after an overnight fast, quite saturated bile from the liver is likely to enter a gallbladder with a large volume. Even after a meal has partially emptied the gallbladder, a relatively large residual volume of bile remains. $G$ allbladder filling is contingent on the rate of hepatic bile secretion, the relative resistance to entry through the cystic duct and within the gallbladder (intra-vesicular pressure), and the metering effect of sphincter of 0 ddi tone. The hepatic secretion rate, in turn, predominantly reflects the portal venous return of bile salts; this is presumably higher in obese people because they empty a larger absolute volume of gallbladder bile and have large bile salt pools. The high refilling rate of the gallbladder may reflect a high rate of hepatic bile secretion - these large individuals empty a large bolus of bile salts into the small intestine that recycles via the enterohepatic circulation - and a relatively low intravesicular pressure (P) (from LaPlace's law [P $\alpha 2 T / r$ ], the large gallbladder residual volume with its elevated radius [ $r$ ] should be associated with a low intravesicular pressure for the same wall tension [T]). A third component, the sphincter of 0 ddi tone, if elevated, could enhance gallbladder filling, but there is no reason to suspect this.

The bariatric surgery performed to restrict intake resulted in a dramatic weight loss in all patients after six weeks. There was also a significant reduction in gallbladder emptying. The patients who developed gallstones were affected the most; their emptying fell outside of the 95th percentile of the group. A II three patients who developed gallstones had a greater weight loss than that recommended for safe weight reduction (4). Two of these patients were out of the 95th percentile for the group. This rapid weight loss led to a depressed gallbladder emptying and a greater gallbladder residual volume. Further, the drop in the refilling rate likely reduced the turnover of gallbladder bile, aggravating stasis. The lowered emptying might have depressed the enterohepatic recycling of bile salts, reducing their flux through the liver and perhaps contributing to a relative higher cholesterol content in bile. The result was gallstone formation in these patients following surgery; particularly associated with brisk weight loss. A fter six months, all gallbladder parameters began to normalize, with gallstones disappearing in one of the patients who had exhibited a significant improvement in all parameters, especially gallbladder emptying. These apparently beneficial changes occurred despite these patients still being obese, likely reflecting the more modest rate of weight reduction.

The advantages of laparascopic gastric banding include a shortened hospitalization and a quicker return to normal oral intake and activity after surgery. The preservation of the normal anatomy of the gastrointestinal tract and of the enterohepatic circulation of bile salts should lessen the predisposition towards gallstone formation. Bile salts secretion is the driving force for bile formation, and with phospholipids, is essential for cholesterol solubilization. Generally, the liver of an obese person secretes cholesterol excessively (31). Rapid weight loss further aggravates this cholesterol hypersecretion, likely through its mobilization from fat. Reduced intake, especially in the weeks following restrictive bariatric surgery, results in less frequent and less effective stimulation of the gallbladder to empty. These conditions cause bile to become more supersaturated with cholesterol because of depressed enterohepatic cycling of bile salts, which lowers their hepatic secretion, and also because of the excessive cholesterol being secreted. Further, bile resides for longer periods in the gallbladder, allowing the necessary time for nucleation and the precipitation of cholesterol microcrystals, crystal aggregation and stone growth. The laparoscopic procedure aims to provide earlier feeding and gradual weight loss compared with the gastric bypass operation, but did not prevent stone formation in those patients with excessive rates of weight reduction. A lthough the numbers in this study are not large, the incidence of gallstones (three out of 11 patients, or $27 \%$ ) is somewhat less than that after gastric bypass surgery for obesity (36\% to $50 \%)(2,32)$, but is similar to that from dietary therapy $(2,5)$.

$\mathrm{G}$ astric banding restricts food intake and hence leads to weight loss. Factors such as meal frequency, total calories consumed and calories as fat all influence gallbladder emptying through the release of CCK. This in turn affects the enterohepatic cycling of bile salts and hence, biliary lipid composition. The standard dose of CCK-8 given to quantitated gallbladder empting in the present study provides a consistent stimulus, but would not necessarily reflect day-to-day changes in the food ingested. Likely the greatly reduced food intake in the first six weeks after surgery would have produced an even further decrease in gallbladder emptying. The apparent adaptation six months later presumably resulted from an improved dietary intake with more effective stimulation of the gallbladder, a decline in the rate of weight loss with less mobilization of cholesterol into bile and a relative improvement in cholesterol saturation. Indeed, the impaired gallbladder contractility evident in patients with cholesterol gallstones reflects the incorporation of this excess cholesterol into the plasma membranes of the gallbladder smooth muscle, altering their structure and function, and causing a defect in receptor-G protein coupling (33-35). During the severe weight loss six weeks after surgery, the greatly increased biliary cholesterol saturation would likely impair gall bladder motility to a greater extent than the lesser weight loss at six months. The present study was not designed to measure all these features. 


\section{CONCLUSIONS}

We have demonstrated that morbidly obese patients have an enlarged fasting gallbladder volume, rather normal gallbladder emptying for its size, increased gallbladder residual volume and a high refilling rate. The weight loss that follows laparoscopic gastric banding surgery, particularly if excessively rapid, results in impaired gallbladder emptying, accompanied by an increase in gallbladder residual volume and a decrease in the refilling rate. Gallstones form as early as six weeks following surgery. Patients who developed gallstones had a greater decrease in their gallbladder emptying and a more pronounced weight loss compared with that of the reminder of the group. Early refeeding and a more gradual weight loss should ameliorate the gallbladder motility impairment and lessen stone formation. G iven these findings, it seems reasonable to keep the rate of weight reduction at less than $1.5 \%$ of weight per week. The adjustable nature of gastric banding operations permits such fine tuning, better controlling weight loss and potentially eliminating the risk of gallstone formation following bariatric surgery.

\section{REFEREN CES}

1. Faloon W W. Hepatobiliary effects of obesity and weight-reducing surgery. Sem Liv Dis 1988;8:229-36.

2. Liddle RA, Goldstein RB, Saxton J. G allstone formation during weight-reduction dieting. A rch Int M ed 1989;149:1750-3.

3. Delaney A G, Duerson M C, O 'Leary JP. The incidence of cholelithiasis after jejunoileal bypass. Int J O bes 1980;4:243-8.

4. W einsier $R L, W$ ilson $L J$, Lee J. M edically safe rate of weight loss for the treatment of obesity: A guideline based on risk of gallstone formation. A m J M ed 1995;98:115-7.

5. Marzio L, Capone F, N eri M, M ezzetti A, De A ngelis C, Cuccurullo F. G allbladder kinetics in obese patients. Effect of a regular meal and low-calorie meal. Dig Dis Sci 1988;33:4-9.

6. Kucio C, Besser P, Jonderko K. G allbladder motor function in obese versus lean females. Eur J Clin N utr 1988;42:121-4.

7. Vezina W C, Paradis RL, G race DM , et al. Increased volume and decreased emptying of the gallbladder in large (morbidly obese, tall normal, and muscular normal) people. G astroenterology 1990;98:1000-7.

8. G ebhard RL, Prigge W F, A nsel HJ, et al. The role of gallbladder emptying in gallstone formation during diet-induced rapid weight Ioss. H epatology 1996;24:544-8.

9. W isen 0 , Johansson C. G astrointestinal function in obesity: M otility, secretion, and absorption following a liquid test meal. M etabolism 1992;41:390-5.

10. Van der Linden W. Emptying of the human gallbladder and predisposition to gallstones formation. Tijdschr G astroenterol 1974;17:121-8.

11. Stone BG, A nsel HJ, Peterson FJ, G ebhard RL. G allbladder emptying stimuli in obese and normal-weight subjects. H epatology 1992;15:795-8.

12. Portincasa P, Di Ciaula A, Palmieri V O, vanBerge-H enegouwen GP, Palasciano $G$. Effects of cholestyramine on gallbladder and gastric emptying in obese and lean subjects. Eur J Clin Invest 1995;25:746-53.

13. A calovschi M, Badea R. U Itrasonographic study of gall-bladder emptying in obese patients. Int J O bes Relat M etab Disord 1992;16:313-5.
14. Marks JW, Bonorris G G, Schoenfield LJ. Effects of ursodial or ibuprofen on contraction of gallbladder and bile among obese patients during weight loss. Dig Dis Sci 1996;41:242-9.

15. Behar J, Lee KY, Thompson W R, Biancani P. Gallbladder contraction in patients with pigment and cholesterol stones. G astroenterology 1989;97:1479-84.

16. M eyer PD, Den Besten L, G urll NJ. Effects of cholesterol gallstone induction on gallbladder function and bile salt pool size in the prairie dog model. Surgery 1978;83:599-604.

17. Doty JE, Pitt HA, Kuchenbecker SL, DenBesten L. Impaired gallbladder emptying before gallstone formation in the prairie dog. Gastroenterology 1983;85:168-74.

18. Fridhandler TM, Davison JS, Shaffer EA. Defective gallbladder contractility in the ground squirrel and prairie dog during the early stages of cholesterol gallstone formation. G astroenterology 1983:85:830-6.

19. Roslyn JJ, DenBesten L, Pitt HA, Kuchenbecker S, Polarek JW. Effects of cholecystokinin on gallbladder stasis and cholesterol gallstone formation. J Surg Res 1981;30:200-4.

20. Delin CR, A nderson PG. A preliminary comparison of the psychological impact of laparoscopic gastric banding and gastric bypass surgery for morbid obesity. O bes Surg 1999;9:155-60.

21. Dodds W J, Groh W J, Darweesh RM A. Sonographic measurement of gallbladder volume. A m J Radiol 1985;145:1009-11.

22. Spellman SJ, Shaffer EA, Rosenthall L. Gallbladder emptying in response to cholecystokinin. A cholescintigraphic study. G astroenterology 1979;77:115-20.

23. Everson GT. Braverman DZ. Johnson ML. Kern F Jr. A critical evaluation of real-time ultrasonography for the study of gallbladder volume and contraction. G astroenterology 1980;79:40-6.

24. Balzer K, G oebell H, Breuer N, Ruping KW, Leder LD. Epidemiology of gallstones in a German industrial town (Essen) from 1940-1975. Digestion 1986;33:189-94.

25. Barbara L, Sama C, M orselli A M . A population study on the prevalence of gallstone disease: The Sirmione Study. H epatology 1987;7:913-20.

26. Jensen $\mathrm{KH}$, Jorgensen $\mathrm{T}$. Incidence of gallstone in a Danish population. G astroenterology 1991;100:790-5.

27. Rayn J, Cohen S. Pressure-volume response to gastrointestinal hormone. A m J Physiol 1976;230:1461-8.

28. Davis M, Ryan J. Influence of progesterone on guinea pig gallbladder motility in vitro. Dig Dis Sci 1986;31:513-9.

29. Palasciano G, Serio G, Portincasa $P$, et al. G allbladder volume in adults, and relationship to age, sex, body mass index, and gallstones: A sonographic population study. A m J G astroenterol 1992;87:493-7.

30. Shaffer EA. Gallbladder sludge: W hat is its clinical significance? Curr G astroenterol Rep 2001;3:166-73.

31. Shaffer EA, Small DM. Biliary lipid secretion in cholesterol gallstone disease. The effect of cholecystectomy and obesity. J Clin Invest 1977;59:828-40.

32. Shiffman M L. Sugerman HJ. Kellum JM. Brewer W H. Moore EW. Gallstone formation after rapid weight loss: A prospective study in patients undergoing gastric bypass surgery for treatment of morbid obesity. A m J G astroenterol 1991;86:1000-5.

33. $\mathrm{X} \cup \mathrm{Q}-\mathrm{W}$, Shaffer $\mathrm{EA}$. The potential site of impaired gallbladder contractility in an animal model of cholesterol gallstone disease. G astroenterology 1996;110:251-7.

34. Shaffer EA. C ontrol of gall-bladder motor function. A liment Pharmacol Ther 2000;14(Suppl 2):2-8.

35. Xiao ZL, Chen Q, A maral J, Biancani P, Behar J. Defect of receptor-G protein coupling in human gallbladder with cholesterol stones. A m J Physiol Gastrointest Liver Physiol 2000;278:G 251-8. 


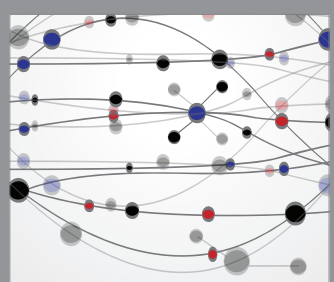

The Scientific World Journal
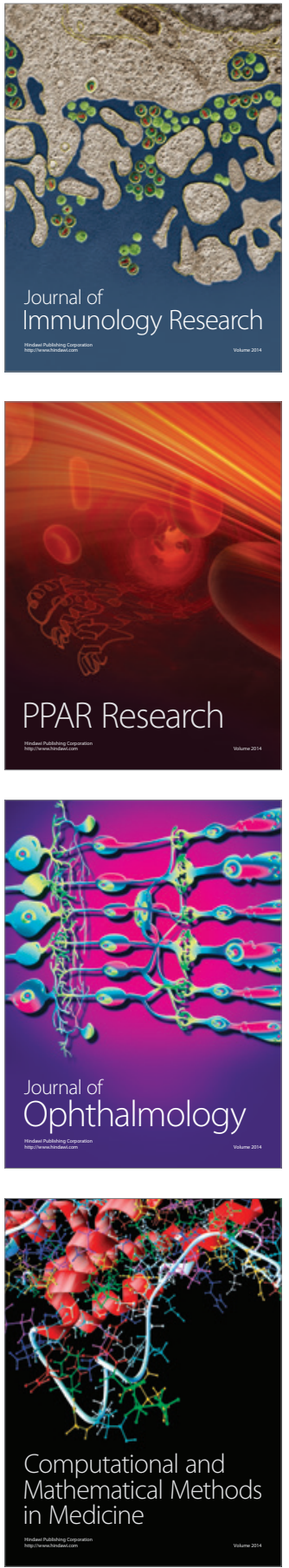

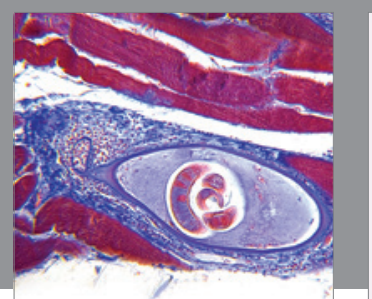

Gastroenterology Research and Practice

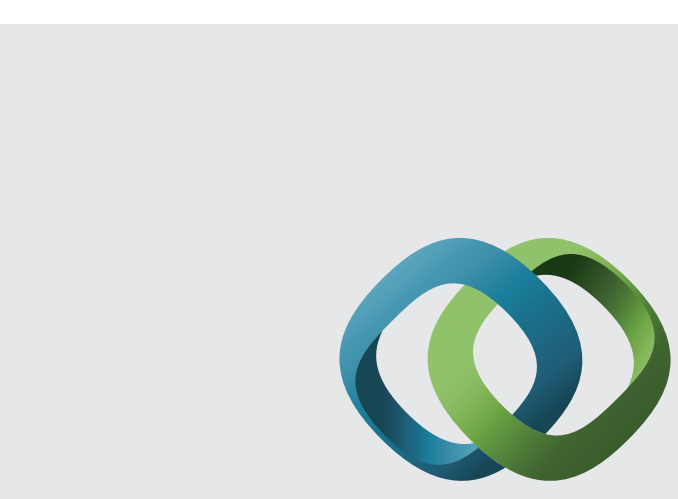

\section{Hindawi}

Submit your manuscripts at

http://www.hindawi.com
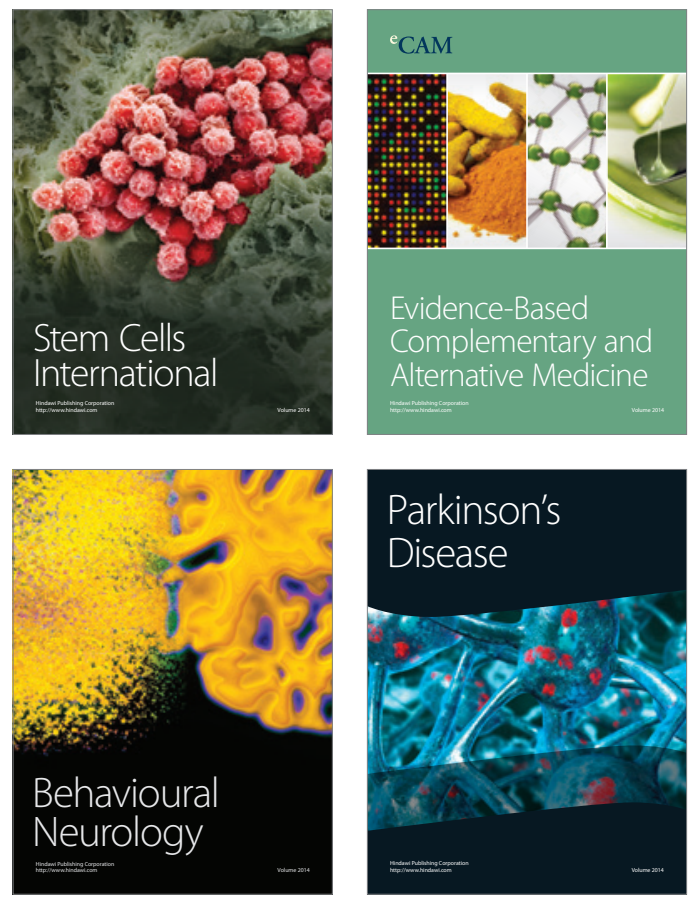
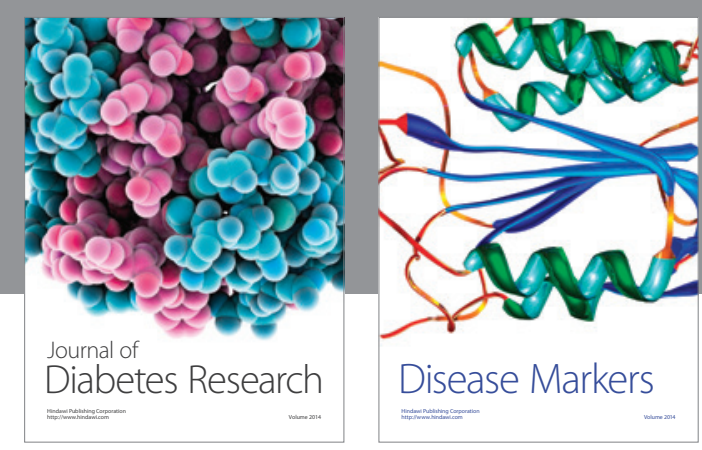

Disease Markers
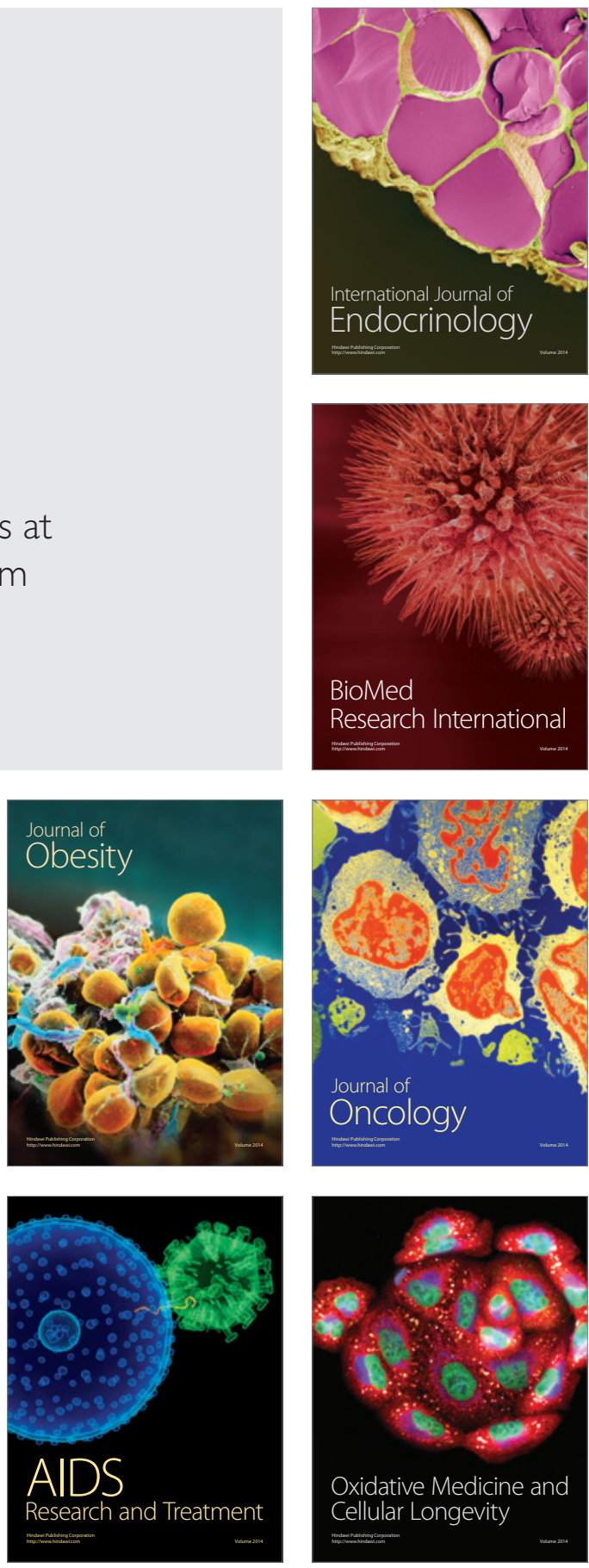